\title{
Anti-Graffiti-Pulver mit hoher Schutzwirkung
}

\author{
Speziell für Innenanwendungen wurde ein neues, chemisch hochresistentes Anti-Graffiti-Pulver \\ entwickelt. Optional kann dieses Pulverlacksystem auch mit antimikrobieller Wirkung geliefert werden.
}

Dadurch erschließen sich neue Anwendungen in Bereichen mit hohen hygienischen Ansprüchen.

—ür Anwendungsbereiche, die gleich- zeitig eine besondere chemische und antimikrobielle Schutzwirkung erfordern, wurde von IGP Pulvertechnik ein neues Mischpulversystem entwickelt. Die hohe chemische Resistenz des Pulverlacks vom Typ IGP-Duraguard 32 ermöglicht den Einsatz von scharfen Reinigern, ohne dabei die pulverbeschichtete Oberfläche zu beeinträchtigen. Dadurch ist eine sehr gute AntiGraffiti-Funktionalität gewährleistet.

Das Pulver ermöglicht einen funktionellen und permanenten Graffitischutz, zum Beispiel für Züge, StraBen- und U-Bahnen, Busse und andere öffentliche Transporteinrichtungen. Darüber hinaus ist das Pulver auch für den Einsatz im Bereich der Stadtmöblierung (Innenanwendung) sowie für Maschinen und Motoren unter Einfluss von Ölen und Bremsflüssigkeit anwendbar. Aktuell kommt das Pulver als glattverlaufendes hochglänzendes System zum Einsatz, weitere Ausführungen sind in Planung. Dabei ist eine einschichtige Applikation möglich. Die so behandelten Oberflächen ermöglichen eine hohe Schlagfestigkeit und Elastizität bei gleichzeitig gutem Schutz gegen Korrosion.

Die Beständigkeit und die optionale Ausstattung mit antimikrobieller Wirkung (Typ IGP-Duracare) eröffnen neue Anwendungen in Bereichen mit hohen hygienischen Ansprüchen.
Anwendungsmöglichkeiten liegen unter anderem im Bereich Krankenhausmobiliar sowie medizintechnische Geräte und Einrichtungen. Auch für den Einsatz in Laboreinrichtungen, Feuchträumen und deren Einrichtungen sowie Lagerräumen mit erhöhten Anforderungen an die Vermeidung von Keimausbreitung ist der Pulverlack geeignet. Weitere Anwendungsgebiete sind die Klimatechnik und Sanitäreinrichtungen.

\section{Kontakt: \\ IGP Pulvertechnik AG, \\ CH-Wil, Tel. +417192981 11, \\ info@igp.ch, www.igp.ch}

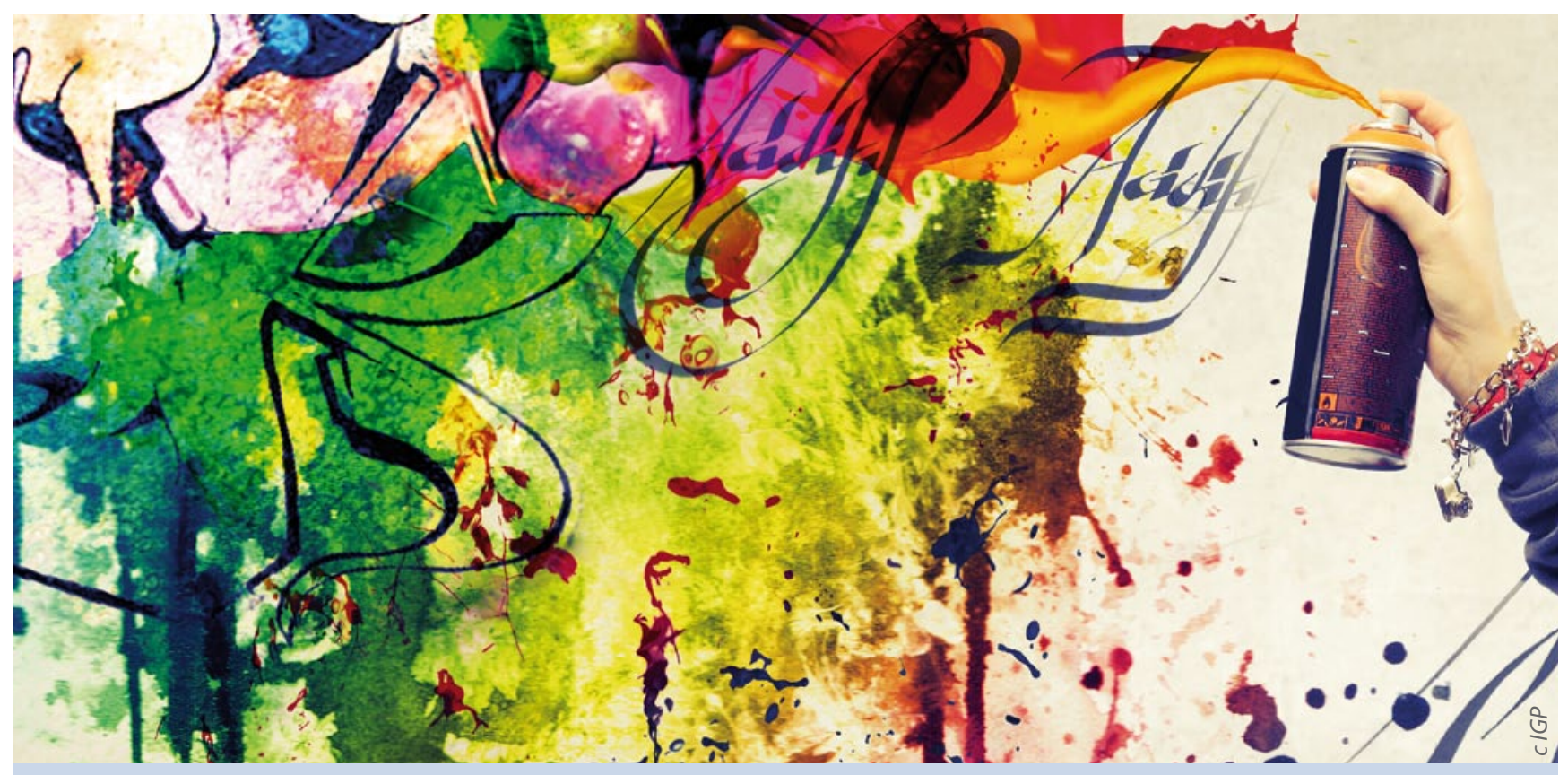

Für Bereiche, die eine besondere chemische Schutzwirkung erfordern, wurde ein neues Mischpulversystem mit Anti-Graffiti-Funktionalität entwickelt. Eine zusätzliche, optionale antimikrobielle Ausstattung erweitert das Einsatzspektrum. 